\title{
Desarrollo del Aparato Digestivo
}

\author{
Digestive System Development
}

*,**Ignacio Roa \& *,*** Manuel Meruane

ROA, I. \& MERUANE, M. Desarrollo del aparato digestivo. Int. J. Morphol., 30(4):1285-1294, 2012.

RESUMEN: El aparato digestivo deriva del endodermo y el mesodermo, que forman su epitelio y la musculatura lisa respectivamente. Al igual que en el resto de los sistemas, existe un interacción epitelio-mesenquimática mediada por moléculas como Hedgehog, BMP y FoxF1 que determinan el crecimiento intestinal en sus ejes principales. Los genes Hox, junto con el resto de las moléculas, participan en la regionalización del sistema digestivo. En sus inicios lo denominaremos intestino primitivo, formado por un tubo endodérmico que deriva del saco vitelino; dividiéndose en intestino anterior, medio y posterior. En esta revisión veremos cómo estos 3 segmentos darán origen a las diferentes estructuras del sistema digestivo en los vertebrados.

PALABRAS CLAVE: Sistema digestivo; Intestino primitivo; Endodermo; Mesodermo.

\section{INTRODUCCIÓN}

El diseño del tubo digestivo está relacionado con la dieta del organismo. Si bien la digestión comienza en la cavidad bucal, el procesamiento del alimento se produce en el tubo digestivo; proceso que involucra la degradación del bolo, la absorción del sus constituyentes disponibles y la eliminación de los restos indigeribles. Debido a que la dieta varía entre distintos grupos de vertebrados, los tubos digestivos pueden ser significativamente distintos entre vertebrados relacionados filogenéticamente.

La mayor parte de los vertebrados tienen un tubo digestivo formado por un esófago, un estómago, intestinos y una cloaca. Por muy distintos que parezcan ser, todos comparten un diseño similar subyacente (Starck, 2003).

El desarrollo del aparato digestivo se rige por un patrón conservado a lo largo de las especies (McLin et al., 2009). En términos muy generales sigue la secuencia de eventos que van desde la gastrulación, formación del intestino primitivo desde el endodermo y aposición de parte de la hoja esplácnica del mesodermo lateral (Gilbert, 2005)

Debido al plegamiento del embrión durante el período somítico, la parte dorsal del saco vitelino queda incluida dentro de éste y constituye el intestino primitivo, un tubo endodérmico que consta de tres partes intestino anterior, intestino medio e intestino posterior (Fig.1a)

La mayor parte del epitelio de revestimiento y de las glándulas del tubo digestivo se originan en el endodermo del intestino primitivo (Wells \& Melton, 1999). El tejido muscular, el conectivo y el peritoneo visceral de la pared del tubo derivan de la hoja esplácnica del mesodermo.

El intestino anterior, cerrado en fondo de saco, contribuye cefálicamente a formar la membrana bucofaríngea junto con el revestimiento ectodérmico que se aplica por fuera. El intestino medio permanece ampliamente comunicado con el saco vitelino ubicado fuera del embrión. El intestino posterior, termina también en fondo de saco y forma junto con el ectodermo, la membrana cloacal (Figs. 1a y b). Del intestino posterior nace una evaginación larga denominada alantoides que se hace extraembrionaria y forma parte del pedículo embrionario y posteriormente se convierte en un anexo embrionario muy importante en la formación de la placenta.

Durante la semana siguiente, (Fig.1b) el intestino primitivo presenta los siguientes cambios, el intestino anterior origina:

\footnotetext{
Programa de Magíster en Ciencias Biológicas, Facultad de Medicina, Universidad de Chile, Chile.

** Depto. Ciencias Básicas Biomédicas, Facultad de Ciencias de la Salud, Universidad de Talca, Chile.

**** Laboratorio de Embriología Comparada, Facultad de Medicina, Universidad de Chile, Chile.
} 


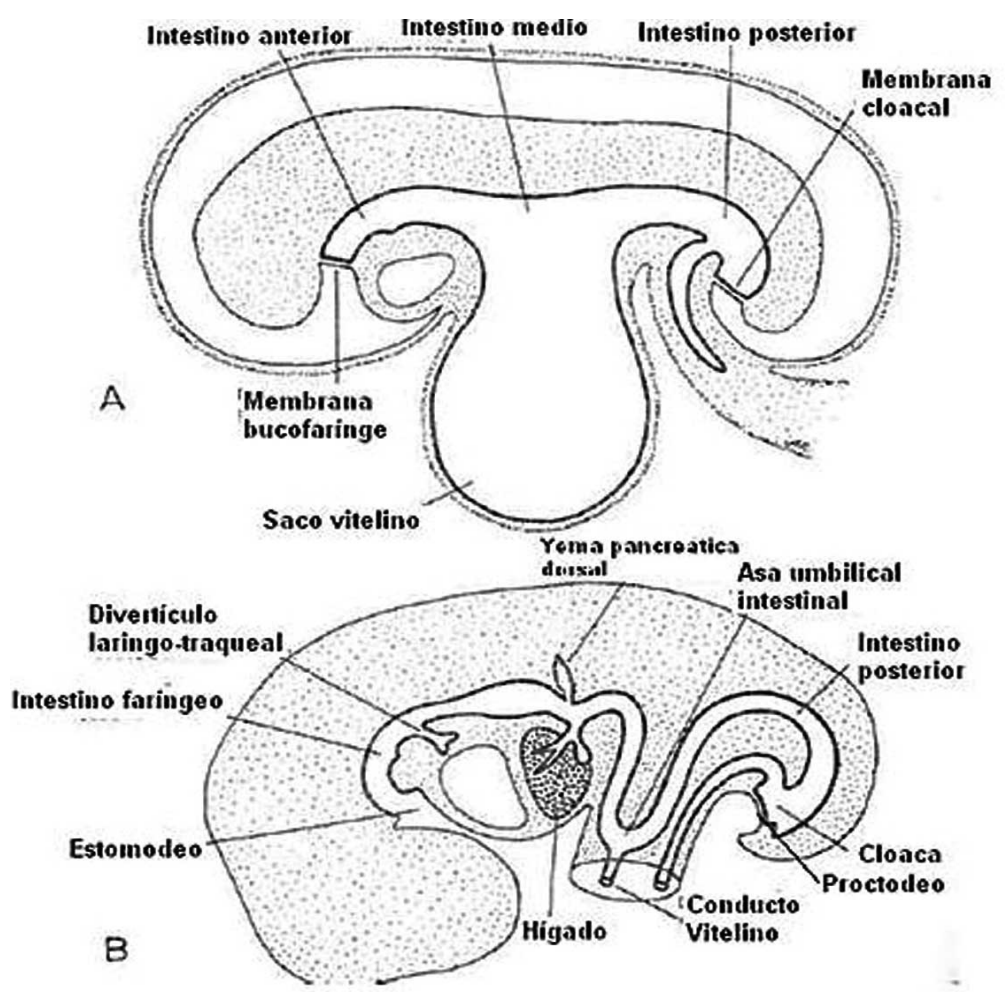

Fig. 1A. Intestino primitivo constituido por intestino anterior, intestino medio e intestino posterior. Se observa además membrana bucofaríngea, saco vitelino y alantoides. Fig. 1B. El intestino anterior se diferencia en dos partes: intestino faríngeo y porción caudal del intestino anterior. El intestino medio da origen a las ramas cefálica y caudal, las cuales están unidas por un conducto vitelino al saco vitelino. El intestino posterior desemboca en la cloaca, terminando en la membrana cloacal. (Modificado de Gomez-Dumm).

1) Una porción cefálica también denominada intestino faríngeo, que se extiende desde la cavidad bucal primitiva o estomodeo hasta el brote traqueo bronquial (también llamado divertículo laringo traqueal), origen del aparato respiratorio.

2) Una porción caudal que se extiende hasta el esbozo hepático. La membrana bucofaríngea desaparece de manera que la boca primitiva (estomodeo) comunica con la región faríngea.

Del intestino medio se origina el asa intestinal primitiva, que mantiene una comunicación con el saco vitelino a través del conducto vitelino y que se extiende desde el divertículo hepático hasta el comienzo del intestino posterior (Fig.1b).

El intestino posterior termina desembocando en una porción dilatada del tubo denominada cloaca, en comunicación con el alantoides y ocluida por la membrana cloacal.

Desarrollo del intestino anterior: Esófago. Se desarrolla a partir del primer segmento del intestino anterior comprendido entre el origen del divertículo respiratorio laringotraqueal y el ensanchamiento que originará el estómago.
En las aves y mamíferos, al principio del desarrollo, el esófago es muy corto, pero posteriormente se alarga debido a la formación del cuello y al descenso del corazón y los pulmones. Durante las primeras etapas del desarrollo el esófago se tiene que separar de la tráquea y esto ocurre gracias a un divertículo traqueo esofágico que los separa. En peces y anfibios el esófago continúa siendo corto aún en las etapas más avanzadas del desarrollo.

Durante un período de tiempo el lumen del esófago esta ocluido totalmente, por una activa proliferación de las células del epitelio y durante el período fetal cuando la gestación esta avanzada ocurre la recanalización del lumen.

Histológicamente, en la mucosa esofágica aparecen glándulas tubulares compuestas de secreción mucosa y está limitada por la muscular de la mucosa de desarrollo muy variable. En peces es una capa de disposición longitudinal, formada por músculo estriado. En anfibios reptiles y aves suele haber dos capas: circular interna y longitudinal externa, ambas de músculo liso. La submucosa presenta glándulas túbulo acinares de secreción mucosa (glándulas esofágicas sólo en mamíferos)

En mamíferos, la túnica muscular del esófago tiene diferente origen, según se trate de la parte superior o inferior de éste. La musculatura estriada, característica del tercio superior, se origina del mesénquima de los arcos braquiales. Sin embargo la musculatura lisa del tercio inferior, se diferencia del mesénquima de la esplacnopleura circundante, tal como ocurre en el resto del tubo digestivo el segmento próximo a su desembocadura en el estómago está formado por músculo liso. La musculatura del esófago tiene una capa longitudinal interna y otra circular externa. En carnívoros y artiodáctilos rumiantes se agrega una tercera capa que es longitudinal externa. Al igual que en la faringe, la parte craneal del esófago no está envuelta por el celoma, y no que se encuentra detrás de la cavidad pleuroperitoneal; luego tras el crecimiento de los pulmones se encontrará en el seno del mediastino y sólo en el diafragma habrá un corto mesoesófago (Noden \& Lahunta, 1990). 

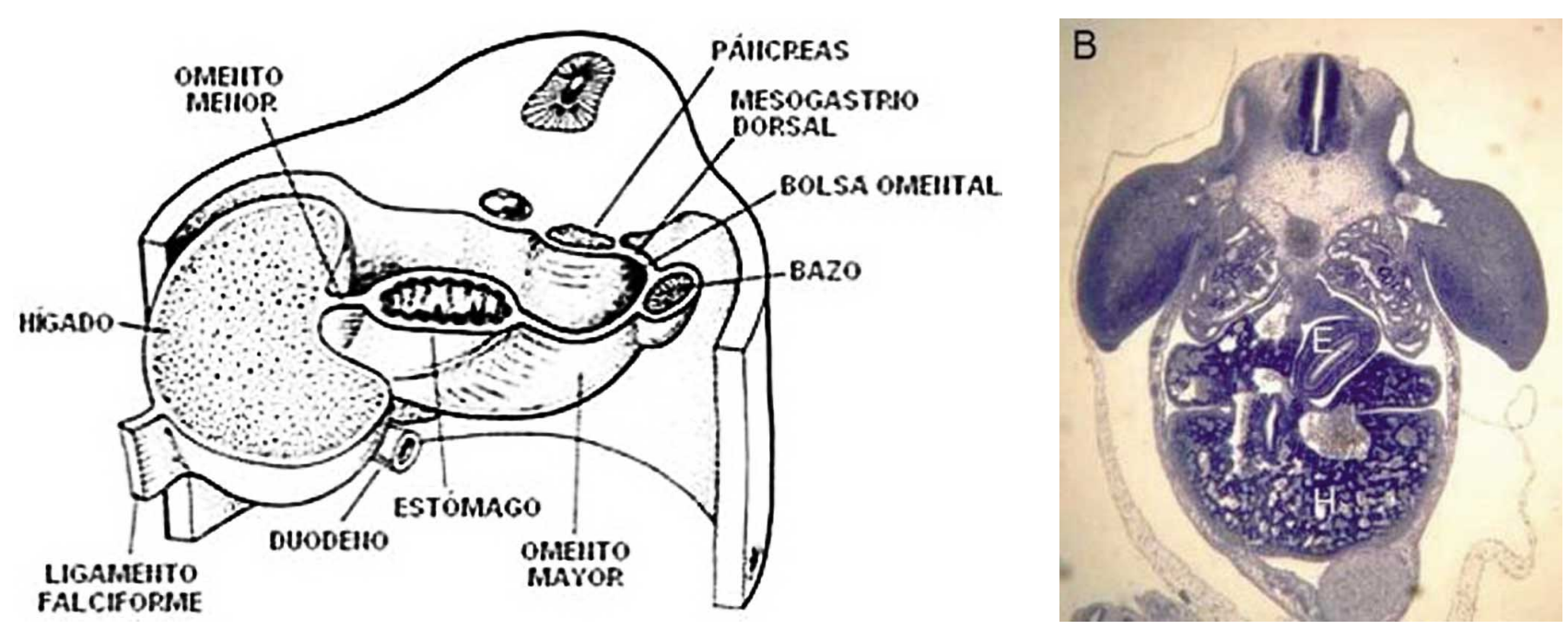

Fig..2. Corte transversal de embrión humano de siete semanas, al cual se le ha quitado la pared ventral del cuerpo. El mesogastrio dorsal crece y se abomba hacia el lado izquierdo, dando origen a la bolsa omental, paralelamente a la rotación del estómago. Modificado de Gomez-Dumm. Figura 2b Corte transversal de embrión de cerdo. Se observa hígado (H), estómago( E) experimentando su rotación. Fotografìa gentileza Dra Mariana Rojas. Lab Embriologìa Comparada.

Especializaciones del esófago: Buche y vejiga natatoria. En muchas aves, al final del esófago se forma una dilatación ventral llamada buche, que permitirá en el futuro almacenar el alimento (Paniagua \& Nistal, 1983). La estructura de este órgano es la misma que la de la pared esofágica. En las palomas (ambos sexos) se forma una masa lechosa en los últimos días de incubación que nutre a los polluelos.

Existe además la vejiga natatoria en los peces, es una dilatación dorsal gaseosa; en los animales menos evolucionados comunica con el esófago a través del canal pneumático; en las formas más evolucionadas este canal desaparece. Sus funciones son: hidrostática para el equilibrio y locomoción, respiratoria en peces de aguas poco oxigenadas y auditiva.

Estómago. El primer esbozo del estómago se reconoce como una dilatación fusiforme del intestino anterior, esta dilatación se forma debido al desigual crecimiento de sus paredes dorsal y ventral, las cuales presentan un índice mitótico distinto. Este es mayor en la pared dorsal que en la ventral, por lo cual crece más rápido que esta última y determina que se pueda identificar una curvatura mayor que es convexa, viene a ser convexa ventral. Más adelante, la porción craneal de la curvatura mayor crece y forma el fundus (Fig. 2).

En la especie humana y en los animales con estómago monocavitario como el gato, el perro y cerdo, tienen lugar dos rotaciones sucesivas que explican su disposición definitiva en la cavidad abdominal.

Primero gira de izquierda a derecha en dirección de los punteros del reloj en aproximadamente, $90^{\circ}$ respecto del eje sagital. De este modo, el lado primitivamente izquierdo se hace ventral y el derecho, dorsal. Además este giro del estómago arrastra consigo al mesogastrio dorsal, determinando en parte, la formación de las trascavidad de los epiplones o bolsa omental. En la figura 2 se puede ver el omento mayor).

La morfogénesis del estómago de los rumiantes (Figs. 3 a y $3 b)$ es inicialmente similar a los restantes mamíferos. En los bovinos en embriones de 5 semanas, el estómago ha rotado aproximadamente $90^{\circ}$ arrastrando la zona de unión del mesenterio dorsal al lado izquierdo. Al principio de la sexta semana el fundus experimenta un marcado crecimiento en sentido craneodorsal y hacia la izquierda, apareciendo el esbozo del rumen (Fig. 3). El retículo se inicia por un pequeño receso de la porción caudoventral del fundus. En el embrión de $28 \mathrm{~mm}$ se reconoce el omaso como un relieve de la curvatura menor. Internamente la luz del estómago esta subdividida en un canal fúndico amplio situado a la izquierda y el canal gástrico a la derecha por la formación de los surcos ventral y dorsal.

Durante la $7^{\circ}$ semana del desarrollo el estómago bovino experimenta un cambio en la orientación y en el ritmo de crecimiento diferencial de cada compartimento. El rumen se desplaza caudodorsalmente con lo que se invierte la posición de sus porciones dorsal y ventral y como resultado de ello el saco ventral definitivo se forma de la porción originalmente dorsal del fundus, los sacos ciegos aparecen más tarde como crecimientos caudales del rúmen (Noden \& Lahunta). 

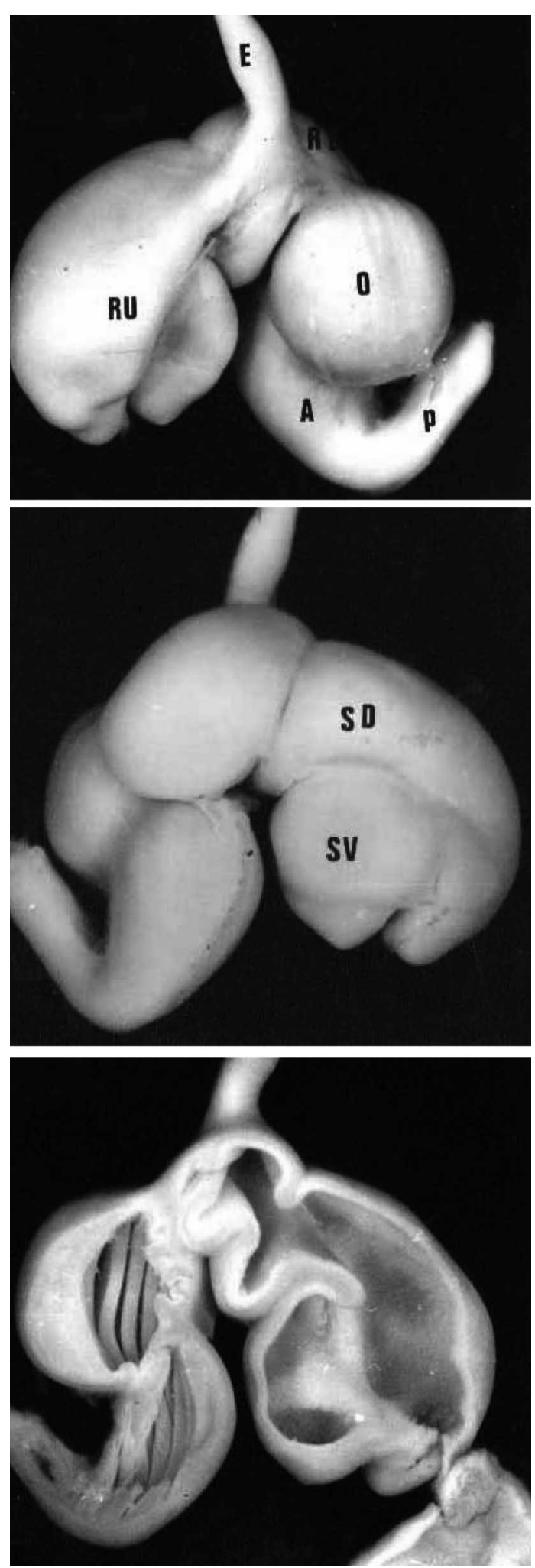

Fig. 3: Estómago en formación de poligástrico (feto de vaca de 58 dìas): Rumen (RU), Omasum (O), Abomasum (A) Retículo (RE), Píloro (P). El rumen presenta un saco dorsal (SD) y un saco ventral (SV). Francisco Estay (1982)
También cambia de posición la porción pilórica del abomaso: se desplaza centralmente y a la derecha, para después incubarse en sentido caudal formando una asa, La región cardial del abomaso crece notablemente durante la segunda mitad de la gestación y se convierte en la cavidad gástrica de mayor tamaño en el neonato (Noden \& Lahunta).

Menos compleja es la mofogénesis externa de retículo y omaso. El primero crece hacia la izquierda y se desplaza en sentido craneal en relación con el resto del estómago (Fig.4) y el omaso permanece en situación ventrolateral derecha. En la $10^{\circ}$ semana ya se han adquirido la mayor parte de los caracteres morfológicos del estómago del bovino adulto aunque el tamaño relativo de las cavidades no queda establecido definitivamente hasta después del nacimiento con el inicio de la alimentación sólida. Estómago anterior. Rumen: 80 \% del volumen del estómago. Reticulum: El $5 \%$ del total. Omasum: El 7-8 $\%$ del total. Estómago posterior (glandular o abomasun): $7-8 \%$ del total; con tres regiones: cardiaca, fúndica y pilórica.

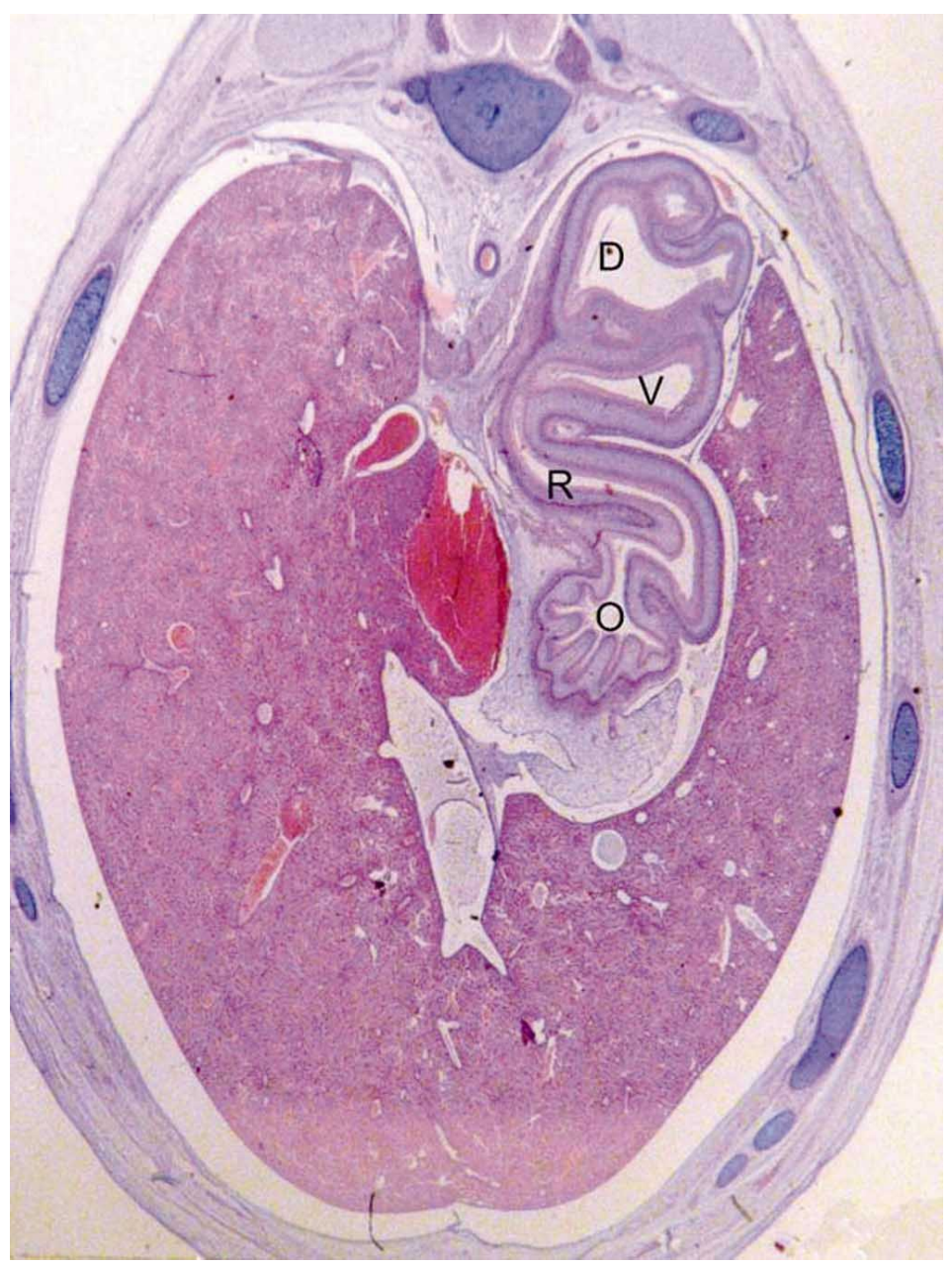

Fig. 4 Corte transversal de un feto bovino de $40 \mathrm{~mm}$ que nuestra el desarrollo del saco dorsal (D) y ventral (V) del rumen, retículo (R) y omasum (O). El Hígado ocupa el lado derecho y el tubo digestivo se encuentra a la izquierda. Fotografía gentileza Dra. Mariana Rojas. Lab. Embrología Comparada. 
El estómago de los rumiantes y sus variaciones morfológicas son el resultado de la adaptación al tipo de alimentos de los diferentes ecosistemas, de este modo su fisiología digestiva es un sistema flexible que permite concentrar los ingerido (Hofmann, 1989).

Estómago de aves Las aves tienen un estómago dividido en dos partes: el estómago glandular o proventriculo y el estómago muscular o molleja. La mucosa del proventrículo es una mucosa con glándulas mucosas y una túnica muscular y corresponde al estómago verdadero. La molleja tiene una musculatura enormemente hipertrofiada, en el futuro servirá para moler el alimento (Fig.5).
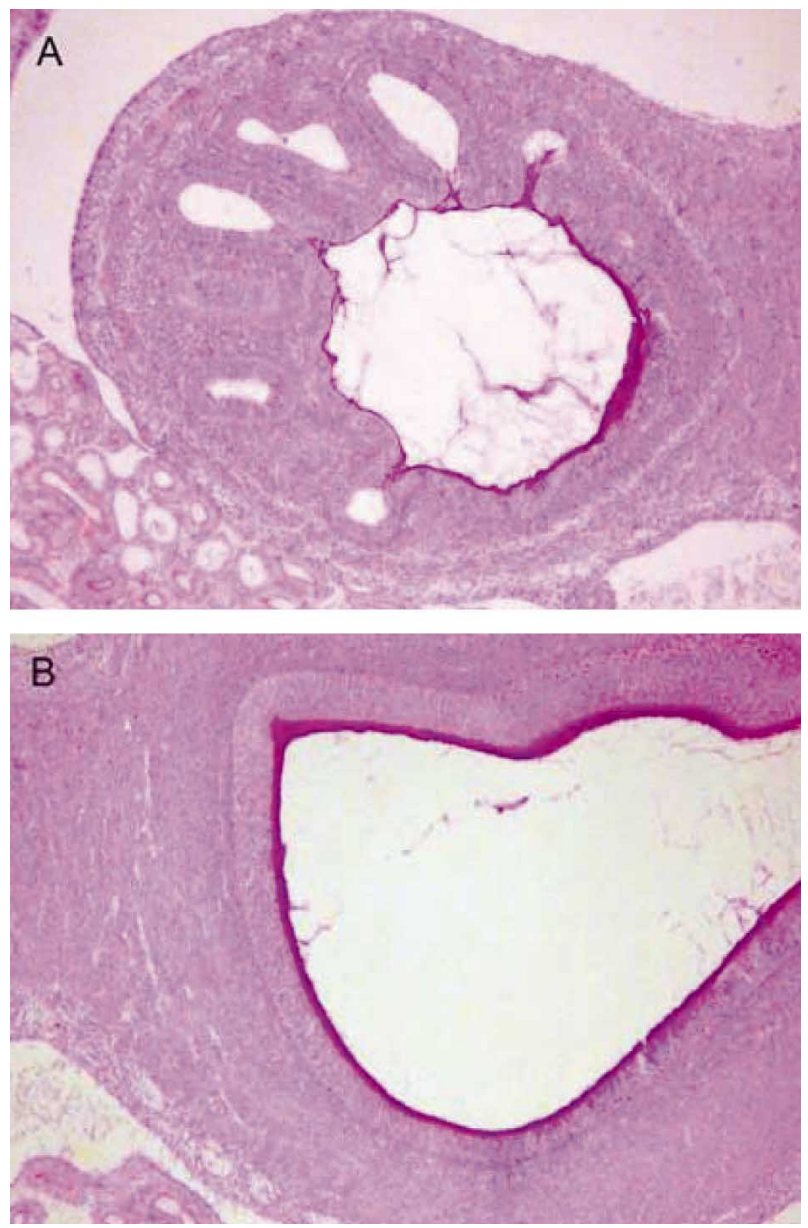

Fig. 5A Corte transversal de estomago verdadero o glandular y Figura 5B estómago muscular de embrión de pollo de 12 días de incubación. 100X Técnica PAS

Estómago de peces. En algunos peces el estómago se proyecta en apéndices digitiformes característicos: los ciegos pilóricos.
Hígado y vesícula biliar. El hígado (Figs. 2, 4 y 6) nace de una evaginación ventral del endodermo del extremo más caudal del intestino anterior. Este divertículo hepático crece cráneo ventralmente en el espesor del mesenterio ventral primitivo (mesogastrio ventral) y en el espesor del mesénquima del septum transversum. El divertículo inicial se divide en dos partes, un esbozo hepático que dará lugar al parénquima del hígado y el esbozo cístico que formará la vesícula biliar, este último esbozo no se desarrolla en las especies que carecen de vesícula biliar, como equinos y roedores de laboratorio.

Las células epiteliales endodérmicas proliferan y forman cordones celulares que se diferenciarán en hepatocitos, otras células derivadas del esbozo hepático dan origen al sistema excretor biliar, es decir, a los conductillos interlobulillares intimamente relacionados con los hepatocitos. El tronco común del divertículo hepático será el conducto colédoco que desemboca en la porción craneal del duodeno en el punto de origen de divertículo El hígado en desarrollo esta ricamente vascularizado por sinusoides venosos en torno de los cordones de hepatocitos. Estos vasos sanguíneos se forman a partir del mesénquima del septum transversum y de las venas umbilicales y vitelinas que atraviesan el septum para alcanzar el seno venoso del corazón.

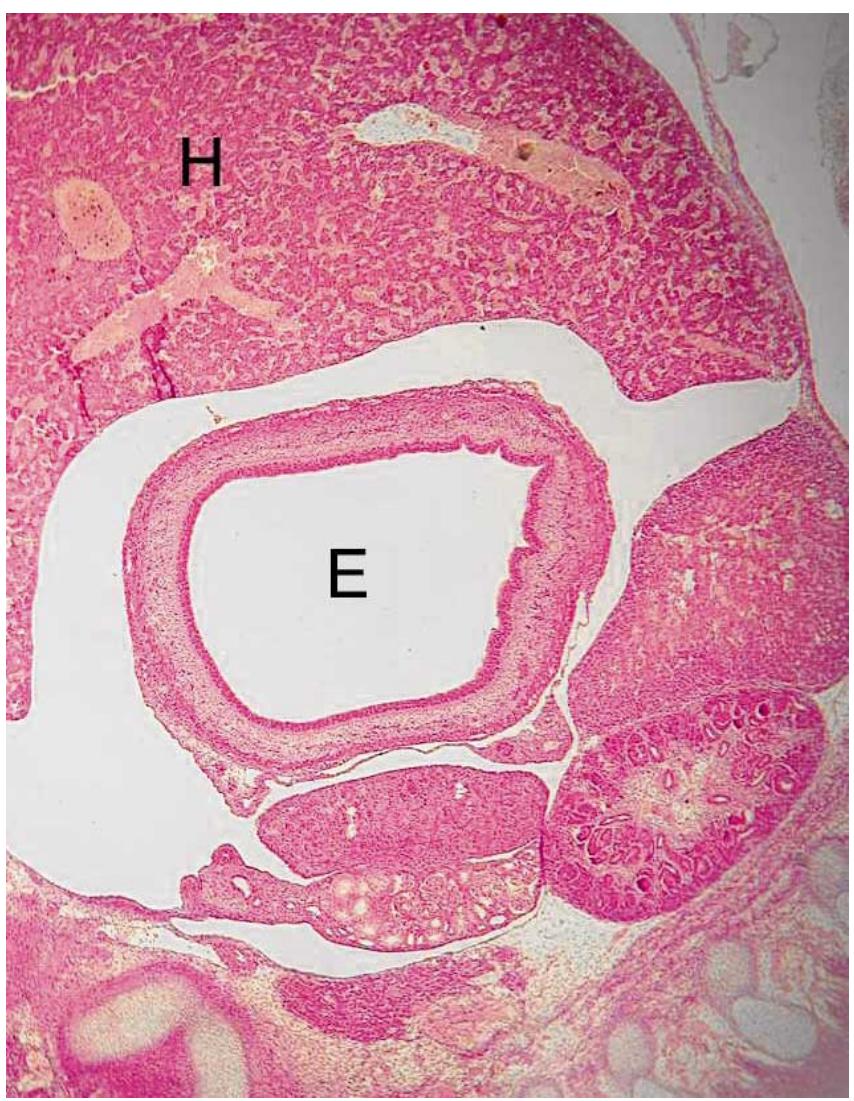

Fig. 6. Desarrollo de Hígado (H), y Estómago (E). H-E Azul de Alcián. 
Páncreas. El páncreas se organiza a partir de dos esbozos, uno ventral y otro dorsal. El páncreas dorsal se origina de la cara dorsal del duodeno, y crece en el mesenterio dorsal (mesoduodeno). El crecimiento se realiza de derecha a izquierda en sentido transversal y da origen al lóbulo izquierdo del páncreas. El esbozo ventral se origina del tronco común del divertículo hepático, por lo que se trata de un derivado ventral del duodeno; pero cuando el divertículo hepático cambia de posición para situarse dorsalmente, arrastra consigo a este esbozo pancreático que alcanza su posición definitiva al fusionarse con el divertículo pancreático dorsal (Figs.7 y 8 )

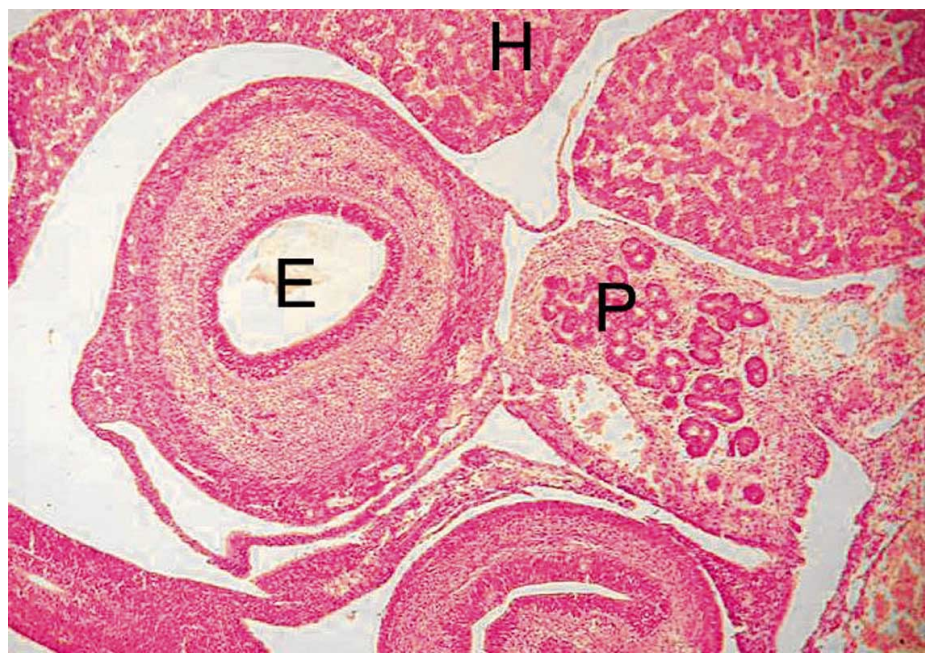

Fig. 7.- Se observa estómago (E), páncreas (P) e Hígado (H).
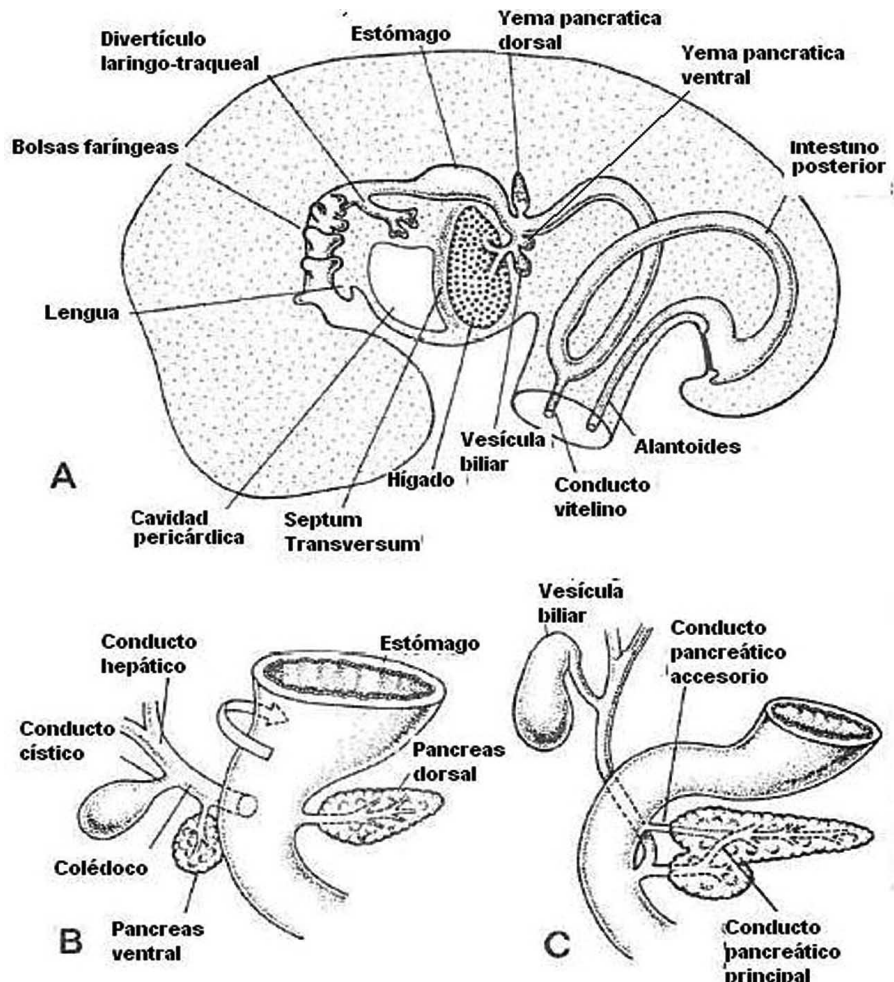

Fig. 8: Rotación del páncreas ventral en el sentido que indica la flecha. Gentileza Dr. Ángel Rodríguez.
El páncreas ventral forma el lóbulo derecho del páncreas y su conducto excretor, el conducto pancreático se abre al duodeno en la papila duodenal mayor junto o adyacente al conducto colédoco. Al fusionarse ambos esbozos pancreáticos forman un cuerpo común, y el sistema de conductos excretores se anastomosan entre sí, de tal modo que la secreción pancreática puede ser vertida al duodeno por uno solo de los conductos o pueden persistir ambos.

Desarrollo del intestino. Una vez que el tubo digestivo primitivo se ha cerrado queda suspendido por un mesenterio dorsal, en un principio corto y rectilíneo, excepto en la zona de formación del asa intestinal donde se hace amplio y en cuyo espesor discurre la arteria vitelina derecha encargada de irrigar el saco vitelino durante su período funcional, para persistir después como arteria mesentérica superior o craneal (Fig.9). Poco después de la formación del asa intestinal desaparece el pedículo de unión con el saco vitelino, lo que permite al asa una gran movilidad dentro del abdomen, y aparece una evaginación en la rama caudal del asa, primer esbozo del ciego, que establece el límite de lo que será intestino delgado y grueso (Fig. 9).

El segmento del intestino anterior inmediatamente caudal al estómago forma el duodeno, que durante los cambios de posición que experimenta el asa intestinal queda fijado por el mesoduodeno a la región dorsal derecha de la cavidad peritoneal.

El rápido crecimiento en longitud del intestino delgado, obliga a la mayor parte de la rama craneal del asa intestinal a situarse fuera de la cavidad abdominal en el interior del cordón umbilical; esta situación se conoce como hernia umbilical fisiológica (Fig.10). Durante el período de exteriorización del asa intestinal continúa creciendo la rama craneal que adquiere una mayor longitud que la caudal (figuras 9); esta elongación asimétrica es la causa de la rotación del asa intestinal que tiene lugar en torno de la arteria mesentérica craneal, de tal modo que la rama craneal pasa caudalmente y a la derecha de la rama caudal. El proceso de rotación continúa hasta que la rama craneal pasa la izquierda y se sitúa cranealmente al resto del intestino medio.El asa intestinal realiza, tomando como eje a la arteria mesentérica craneal, una rotación de unos 270 grados en el sentido de las agujas del reloj cuando se observa dorsalmente.

La secuencia de reincorporación del asa in- 


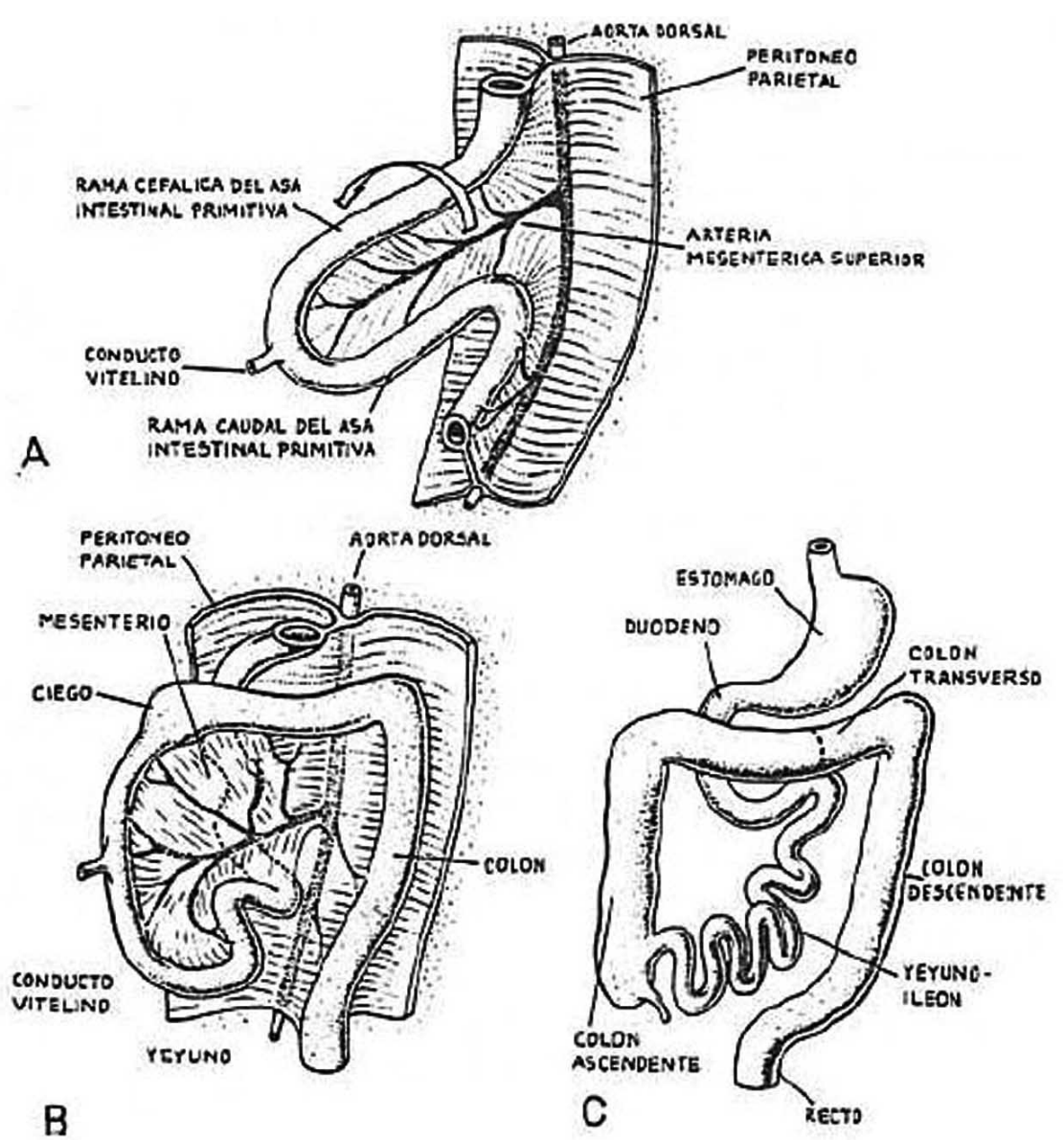

Fig. 9(A). Asa intestinal con ramas cefálica y caudal. (B y C) cambios posteriores al retorno de la hernia umbilical fisiológica. Gentileza Dr. Ángel Rodríguez.

testinal a la cavidad peritoneal determina la disposición definitiva del intestino. La rama craneal que da lugar a la rama ascendente y a la mayor parte del yeyuno, es el primero en volver al abdomen y se sitúa a la izquierda del plano medio; el bloque de asas yeyunales ocupa la parte ventral del abdomen y su porción distal pasa cranealmente al lado derecho.

Cuando la rama caudal se reintegra a la cavidad peritoneal, el ciego y el ileon pasan directamente al lado derecho, cruzando por delante a la arteria mesentérica craneal, quedando en situación el colon descendente y el colon transverso y la flexura cólica izquierda; alcanzada esta posición, el ciego se desplaza caudalmente y a corta distancia de la arteria mesentérica craneal y a su derecha, para formar la flexura cólica derecha y el colon ascendente (Fig. 9).

Fig. 10: Rotación del intestino medio y formación de la hernia umbilical fisiológica,en el interior del cordón umbilical. A) Embrión de ratón (hernia umbilical en círculo). B) Embrión de oveja en período prefetal.
Otras diferenciaciones del Intestino: Válvula espiral. En lampreas, peces sélacos, y dipnoos (peces pulmonados) el intestino desarrolla un profundo pliegue de su pared, de trayecto espiralmás o menos apretado llamado válvula espiral (Fig.11) que aumenta notablemente la mucosa sin aumento de longitud del tubo. El pliegue es inicialmente rectilíneo en el embrión, a lo largo del borde mesentérico intestinal, para luego desarrollarse por un complejo mecanismo de torción. En los peces teleósteos y tetrápodos el Intestino es alargado y contorneado, esto es más acusado en herbívoros que en carnívoros. En aves y mamíferos tienen microvellosidades intestinales y ciegos ( 2 en aves y 1 en mamíferos).
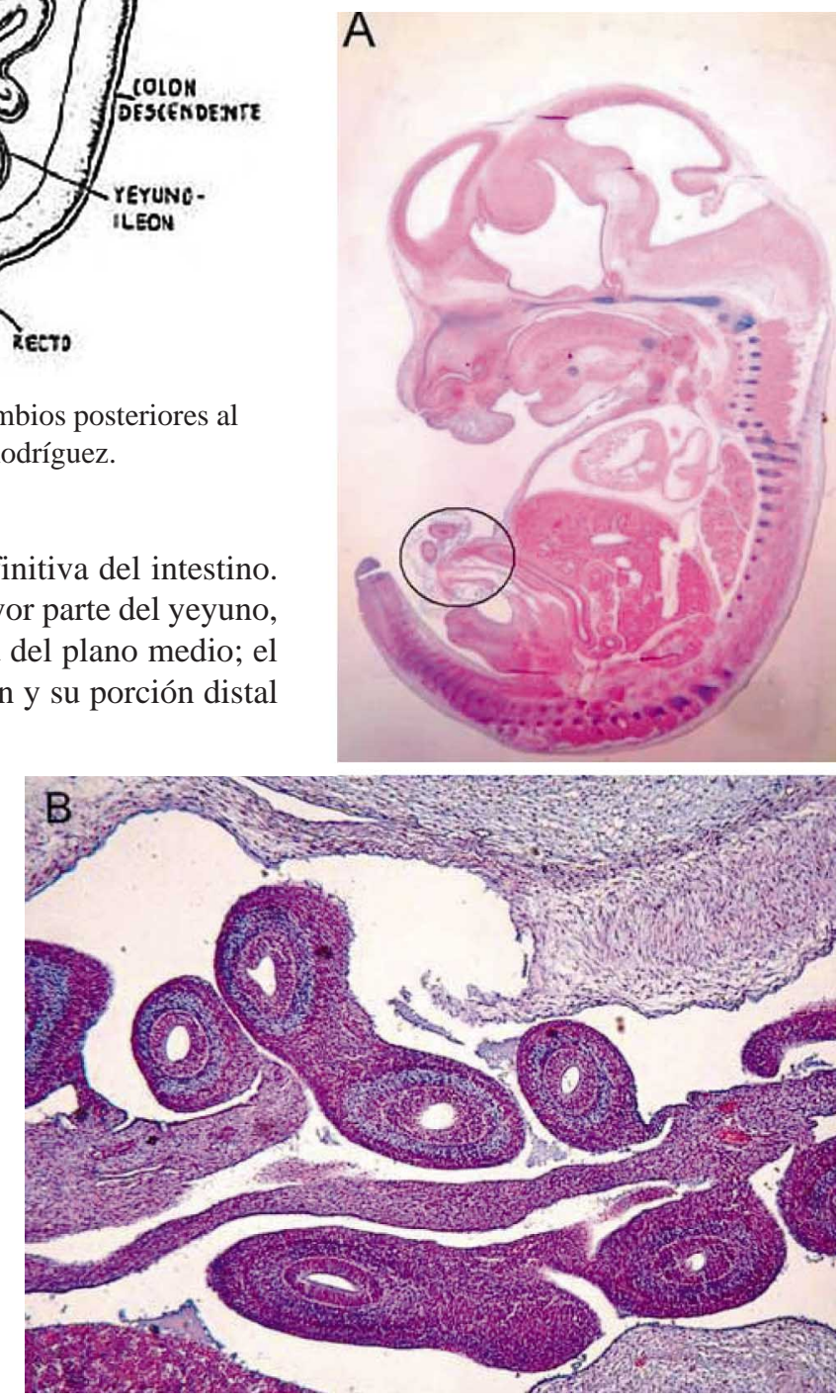

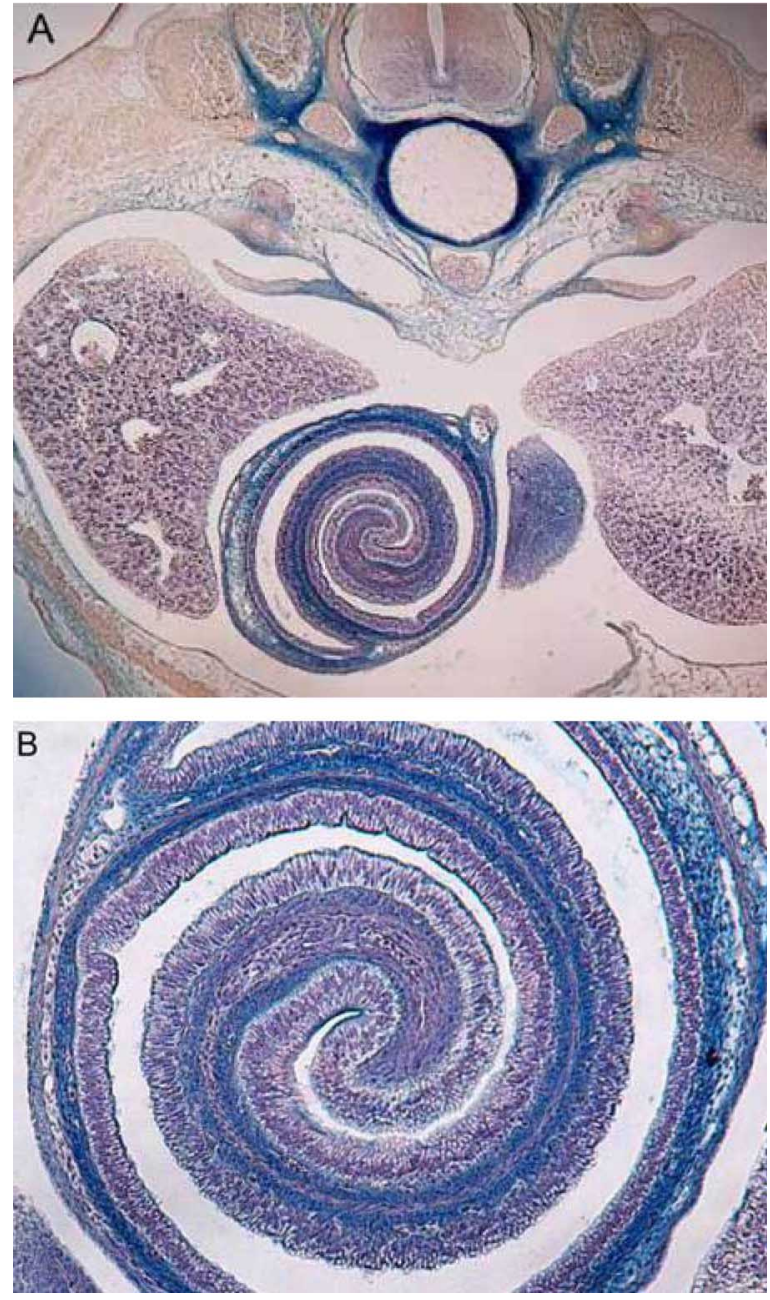

Fig. 11A Corte tranversal de embrión de raya, 50X Se observa válvula espiral e hígado. Fig. 11B 400X. Gentileza Dra Mariana Rojas Lab Embriología Comparada.

Desarrollo del colon. En los carnívoros el colon ascendente es corto y recto, situado en la región dorsal y derecha del abdomen entre el íleon y el colon transverso; unido a su porción inicial se encuentra el ciego, pequeño y de forma espiroidal.

En los rumiantes, el punto medio del colon ascendente se desplaza caudalmente alrededor de la raíz del mesenterio. Para continuar cranealmente por el lado izquierdo, a donde acaba arrollándose en una espiral plana. El ciego es cilíndrico y liso situado dorsalmente en el lado derecho del abdomen, con su extremo ciego en dirección caudal.

Un proceso similar se sigue en el desarrollo del colon ascendente en el cerdo, con la diferencia que la porción que se arrolla en espiral adopta una disposición cónica en lugar de plana, con su base sobre el lado izquierdo del mesenterio. El ciego es abollonado y es arrastrado por el colon ascendente hacia la izquierda en la región dorsal del abdomen.

En peces y anfibios no hay ciego, ya que este aparece en reptiles. En aves suele haber dos ciegos que participan en la hidrólisis del almidón, inversión del azúcar y degradación proteica. En especies que digieren hojas de plantas hay enzimas que degradan la celulosa

Subdivisión de la cloaca. La porción caudal del intestino posterior embrionario forma la cloaca que sirve de reservorio común a los aparatos digestivo y urinario. De esta porción del intestino anterior se desarrolla el alantoides que se inicia en su cara ventral como divertículo que crece cranealmente hasta pasar por el orificio umbilical al celoma extraembrionario, donde participa en la formación de la placenta en los animales domésticos. La cloaca está cerrada por la membrana cloacal que resulta de la fusión del endodermo del intestino posterior y el ectodermo superficial. El mesénquima que rodea a la membrana cloacal prolifera formando un relieve circular, con lo que ésta queda en el fondo de una depresión el proctodeum. Los conductos mesonéfricos desembocan en la cloaca lateralmente.

El intestino posterior y el alantoides están rodeados por mesoderma esplácnico, el primero queda suspendido de la pared dorsal del abdomen por un mesenterio dorsal y el alantoides se fija a la pared ventral por un pliegue del mesodermo esplácnico; no existe unión mesentérica entre ambos.

En el ángulo de unión del alantoides con el intestino posterior, el endodermo y el mesénquima que lo recubre, crecen en sentido caudal formando el tabique urorectal que divide a la cloaca en dos cámaras; la cámara dorsal en relación con el intestino formara el recto y parte del canal anal, la cámara ventral que se continúa con el alantoides forma el seno urogenital. Cuando termina la separación con la fusión del tabique urorrectal y la membrana cloacal, esta queda dividida en dos partes, una dorsal o membrana anal y otra ventral o membrana urogenital, el tejido que separa estas dos láminas forma el cuerpo perineal y su superficie externa el periné.

La membrana anal queda en una depresión, la fosa anal, y cuando degenera se establece la comunicación con el exterior a través del canal anal que estará revestido en su primera porción por endodermo y en su tramo terminal por ectodermo (Fig. 12).

La porción intraabdominal del alantoides inmediatamente craneal a la desembocadura de los conductos mesonéfricos, crece ampliamente para formar la vejiga urinaria; el resto del alantoides se extiende desde el vértice de la vejiga hasta el om- 


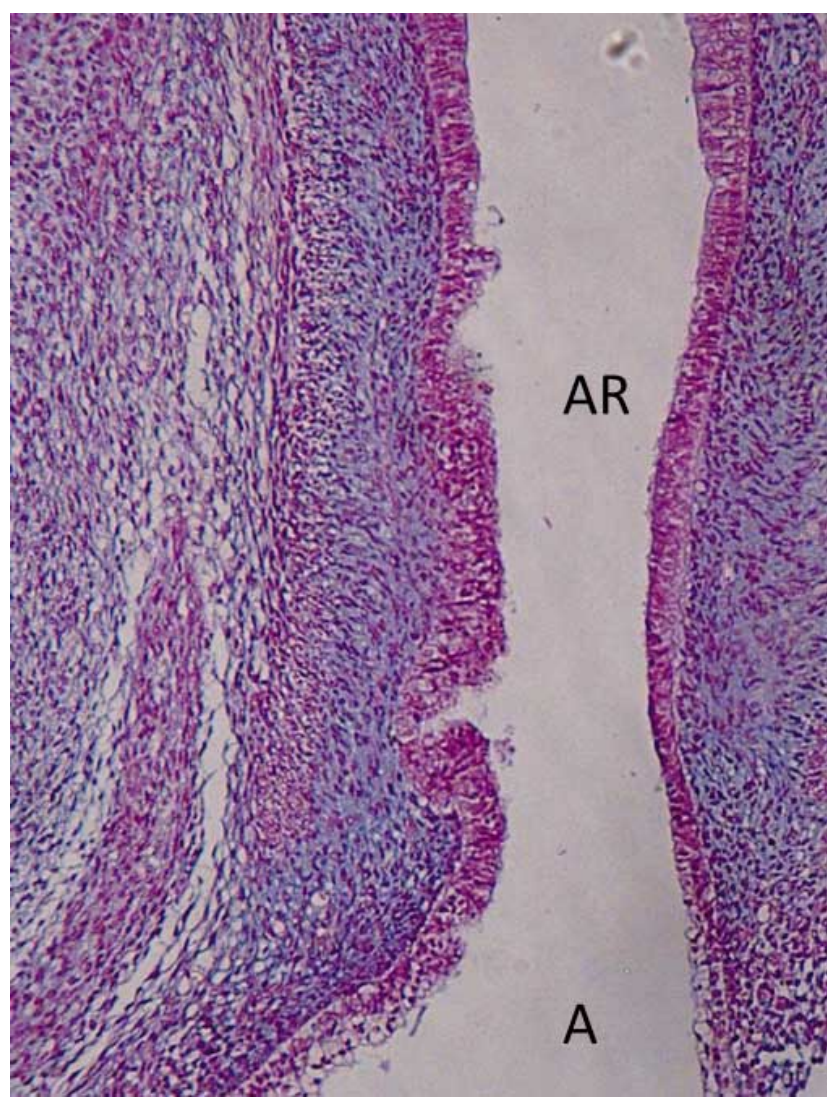

Fig. 12: Canal anal (A) y conducto anorectal (AR) de feto de cerdo. H-E Azul de Alcian.

bligo formando el uraco que persiste permeable durante la vida fetal y permite el paso de la orina a la cavidad alantoidea. En algunos vertebrados como ciclóstomos, algunos teleosteos y aves hay una dilatación o cloaca al final del intestino grueso que sustituye al recto. En la cloaca hay estructuras relacionada con el sistema linfoide en aves.

\section{Eventos moleculares relacionados con el desarrollo del} aparato digestivo. Como hemos visto a lo largo de este capítulo, durante la morfogénesis gastrointestinal el endodermo y el mesodermo sufren una regionalización, elongación y giros. Simultáneamente las células de la cresta neural invaden el intestino para formar el sistema nervioso entérico. Este período de rápido crecimiento es caracterizado por señales regionales que derivan principalmente del mesodermo y otorgan el patrón de los futuros dominios intestinales en 4 ejes: antero-posterior, dorsoventral, derecha-izquierda y radial. De este modo se genera una interacción endodermomesodermo con señales instructivas y permisivas (McLin et al.).

Aunque el mesodermo tiene un rol muy importante en el desarrollo temprano del aparato digestivo, esta formación requiere de señales desde el endodermo, mediadas en parte por la familia de moléculas señalizadosras Hedgehog (SHH e IHH), esta vía se conserva a través de las especies (Deschamps \& van Nes, 2005). La respuesta a las señales Hedgehog a los largo del eje craneocaudal llevan a la formación del intestino anterior, medio y posterior.

En el desarrollo del mesodermo visceral participan Shh, BMP-4 y FoxF1. Estudios en pollo han demostrado que la señal endodérmica Shh activa la expresión de BMP4 en el mesodermo lateral, regulando la proliferación mesodérmica y la diferenciación posterior en músculo liso (Roberts et al., 1998). En el embrión de Xenopus, BMP-4 activa la expresión del factor de trascripción FoxF1 (Tseng., et al., 2004). En ratón la expresión de FoxF1 depende de las señales de Shh desde el endodermo (Mahlapuu et al., 2001).

Los genes Hox confieren información respectos a los límites en la regionalización del intestino, de este modo otorgan información posicional. En embriones de pollo las señales de BMP y ácido retinoico son necesarias para la expresión de los genes Hox en el endodermo. Además existe evidencia de una vía Hedge Hog-hacia-Hox (McLin et al.)

Nos referiremos como patrón de crecimiento radial al desarrollo de vellosidades y criptas. Se ha visto la vía de señalización Hedgehog sirve de morfógeno radial, afectando la posición celular y las decisiones proliferativas entre el mesénquima y el epitelio. La familia BMP también es importante en la formaciones de vellosidades y en el patrón de formación endodérmico/epitelial, mediando relaciones epitelio-mesenquimáticas, de hecho la inhibición de BMP genera un número exagerado de criptas (Batts et al., 2006). Wnts y FGFs también cooperan con Hedgehog y BMP durante el patrón radial del intestino.

ROA, I. \& MERUANE, M. Digestive system development. Int. J. Morphol., 30(4):1285-1294, 2012.

SUMMARY: The digestive system is derived from the endoderm and mesoderm, which form its epithelium and smooth muscle, respectively. As in the other systems, there is an epithelialmesenchymal interactions mediated by molecules such as Hedgehog, BMP and FoxF1, determining intestinal growth in the main axes. The Hox genes, together the rest of the molecules, involved in the regionalization of the digestive system. In the beginning we call it primitive gut, consisting of a tube derived of endodermal yolk sac, divided into foregut, midgut and hindgut. In this review we will see how these 3 segments give rise to different structures of the digestive system in vertebrates.

KEY WORDS: Digestive system; Primitive gut; Endoderm; Mesoderm. 


\section{REFERENCIAS BIBLIOGRÁFICAS}

Batts, L. E.; Polk, D. B.; Dubois, R. N. \& Kulessa, H. BMP signaling is required for intestinal growth and morphogenesis. Dev. Dyn., 235:1563-70, 2006.

Deschamps, J. \& van Nes, J. Developmental regulation of the Hox genes during axial morphogenesis in the mouse. Development, 132:2931-42, 2005.

Estay, F. Desarrollo embrionario del bovino (Bos taurus). Tesis para optar al título de Médico Veterinario. Facultad de Ciencias. Veterinarias y Pecuarias, Universidad de Chile, Santiago, Chile, 1982.

Gilbert, S. Biología del Desarrollo. $7^{\mathrm{a}}$ ed. Buenos Aires, Editorial Médica Panamericana, 2005. p.546.

Hofmann, R. Evolutionary steps of ecophysiological adaptation and diversification of ruminants: a comparative view of their digestive system. Oecologia, 78:443-57, 1989.

Mahlapuu, M.; Enerback, S. \& Carlsson, P. Haploinsufficiency of the forkhead gene Fox 1, a target for sonic hedhehog signaling, causes lung and foregut malformations. Development, 128:2397-406, 2001.

McLin, V. A.; Henning S. J. \& Jamrich M. The role of the visceral mesoderm in the development of the gastrointestinal tract. Gastroenterology, 136:2074-91, 2009.

Noden, D. \& Lahunta, A. Embriología de los animales domésticos. España, Editorial Acribia, 1990. pp. 319-39.

Paniagua, R. \& Nistal, M. Introducción a la Histología Animal Comparada. Barcelona, Labor Universitaria, 1983.

Roberts, D. J.; Smith, D. M.; Goff, D. J. \& Tabin, C. J. Epithelialmsenchymal signaling during the regionalization of the chick gut. Development, 125:2791-801, 1998.

Starck, M. Shaping up: how vertebrates adjusts their morphology to changing environmental conditions. Animal Biol., 53:24557, 2003.

Tseng, H. T.; Shah, R. \& Jamrich, M. Function and regulation of FoxF1 during Xenopus gut development. Development, 131:3637-47, 2004.

Wells, J. M. \& Melton, D. A. Vertebrate endoderm development. Annu. Rev. Cell Dev. Biol., 15:393-410, 1999.
Dirección para correspondencia:

Dr. Ignacio Roa

Depto. Ciencias Básicas Biomédicas

Facultad de Ciencias de la Salud

Universidad de Talca

CHILE

E-mail: iroa@utalca.cl

Recibido : 12-02-2012

Aceptado: $26-05-2012$ 